\title{
MPPT based Charge Controller for Off Grid Small Wind Machine using PWM Technique
}

\author{
Priyanka P. Alawekar \\ Department of Technology, \\ Shivaji University \\ Kolhapur
}

\author{
U.L.Bombale \\ Professor, Department of \\ Technology, Shivaji University \\ Kolhapur
}

\author{
N.N.Shinde \\ Professor, Department of \\ Technology, Shivaji University \\ Kolhapur
}

\begin{abstract}
Wind is the most promising renewable source. However its erratic behavior hampers the output especially when the energy generated is to be stored safely and used as per demands. The paper revel the charging battery with maximum power point tracking (MPPT) considering battery safety. The main task of wind power charge controller is to control the flow of charge to and from the battery and protect it from over charging and deep discharging. It regulates flow of charge by monitoring the battery voltage and wind variations continuously. The charge controller developed takes care of weak winds while battery charging and improves the efficiency. Upon fully charging the charge controller disconnects the battery from wind panel to avoid excess charging thus the battery life is increased.

Further the performance of the wind charge controller is evaluated and the results shows that use of PWM technique with MPPT increases the efficiency of charge controller up to 92\% under different laboratory conditions as compared to normal charge controllers without MPPT having efficiencies up to 52 to $60 \%$.
\end{abstract}

\section{Keywords}

Battery safety, charge controller, Maximum power tracking, Off-grid small Wind mill.

\section{INTRODUCTION}

The existing charge controllers are based on analog electronic components like operational amplifiers to amplify the input electrical signal, transistors which are used as switch, silicon controlled rectifiers which passes high current through them and MOSFETs which acts as electronic switch at high current. However the input available power is not tracked and the conversion efficiencies are low. The charge conversion efficiency also can be increased .The effort is made to develop such charge controller using MPPT /PWM techniques.

\section{SYSTEM ARCHITECTURE}

The basic blocks of the wind power charge controller system analyzed here are shown in Fig.1. Since the wind mill power fluctuates with wind velocity, the generator output voltage varies continuously. The dc voltage is then regulated to obtain constant voltage by controlling the duty cycle ratio of a DC to DC converter. The suitable battery bank of $12 \mathrm{~V} / 24 \mathrm{~V} / 48 \mathrm{~V}$ is to be connected at charge controller output. The proposed system will switch off the supply from wind station on complete charging of battery and again switch ON the supply on discharging below certain minimum voltage level to avoid battery from over charging and deep charging respectively. The system is microcontroller based which shall provide accurate results depending upon input variation; it will be user friendly system with LCD display on board.

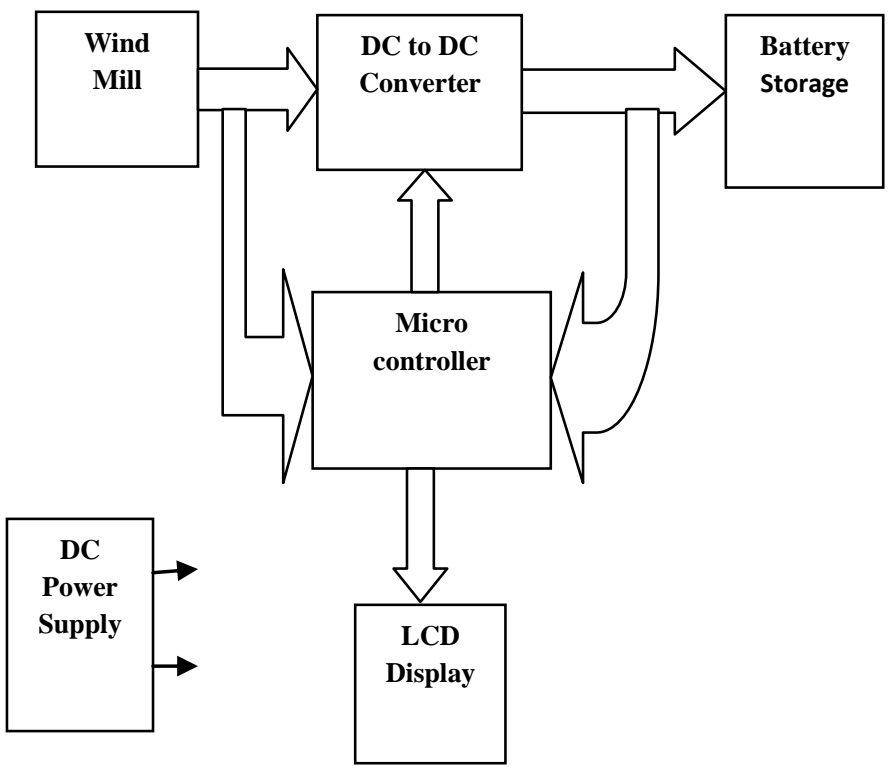

Figure 1: Block diagram of wind power charge controller

\section{SYSTEM DESIGN}

The System Schematic Diagram is shown in Fig.2.

The main parts of system are mentioned as follow

a) DC to DC converter

b) Microcontroller

c) Charging current detection of circuitry

d) Voltage detection of wind mill and battery circuitry

e) LCD Display

f) DC power supply

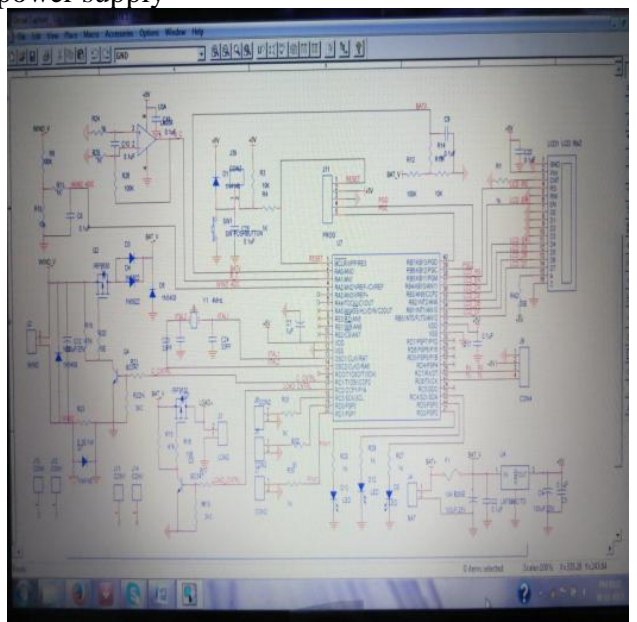

Figure 2: System schematic diagram 


\section{EXECUTION PROCESS}

A typical execution of the program is illustrated in flow chart given in figure 3 .

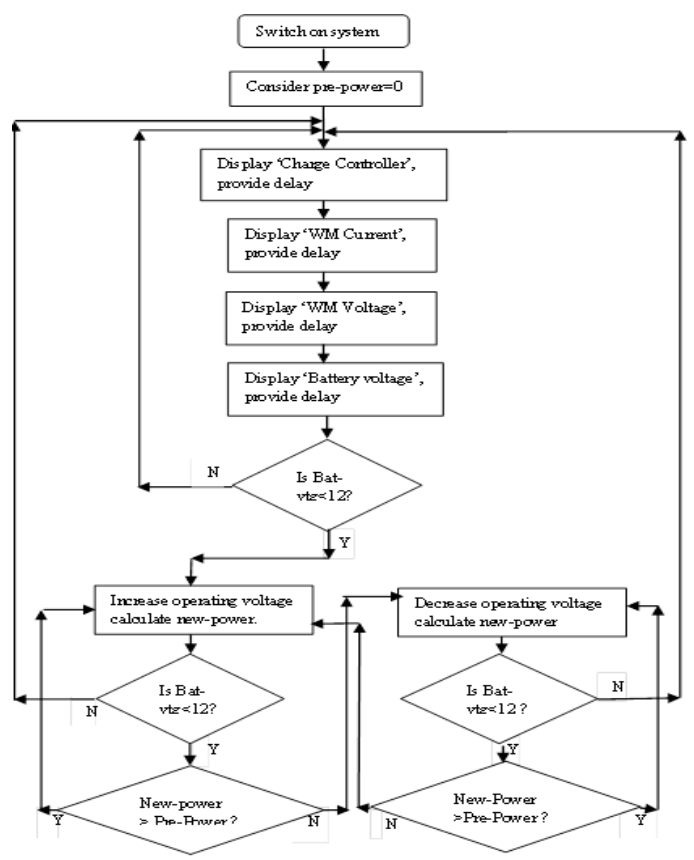

Fig 3: General flow chart

\section{HARDWARE LABORATORY SET-UP}

A laboratory set up with variable speed drive is used for varying input conditions equivalent to real life small wind machines for testing of MPPT based charge controller .Fig 5 explains the test set up .The performance of the device is evaluated based on actual measurements of input /output conditions.

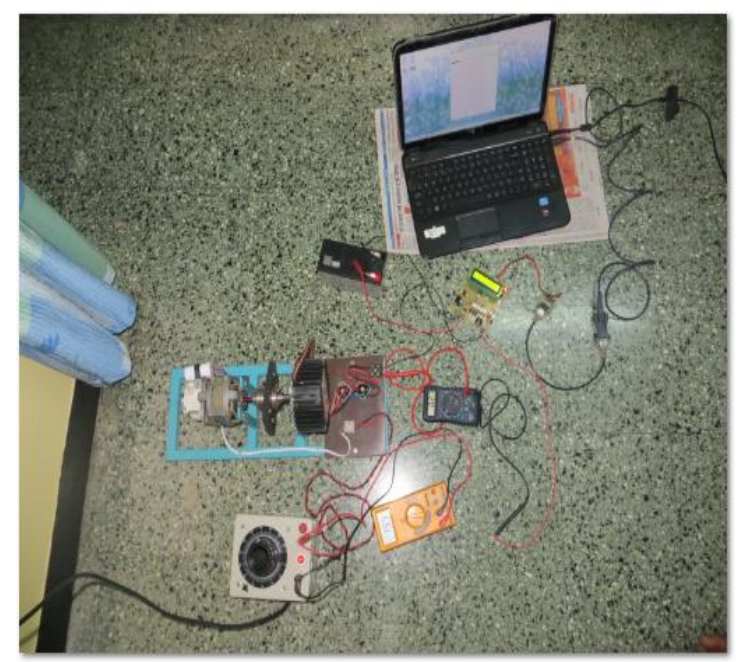

Fig 4: Laboratory testing setup

\section{RESULTS}

1) Graph of Generator RPM Vs Generator O/P Current

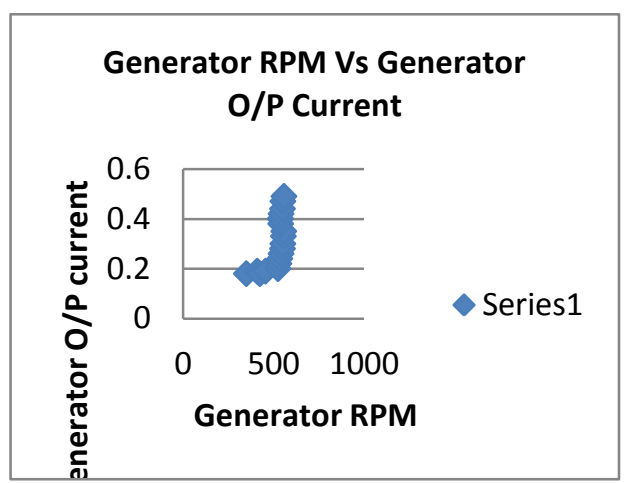

Figure 5: Graph of Generator RPM Vs Generator O/P Current

2) Graph of Generator RPM Vs Generator O/P Voltage

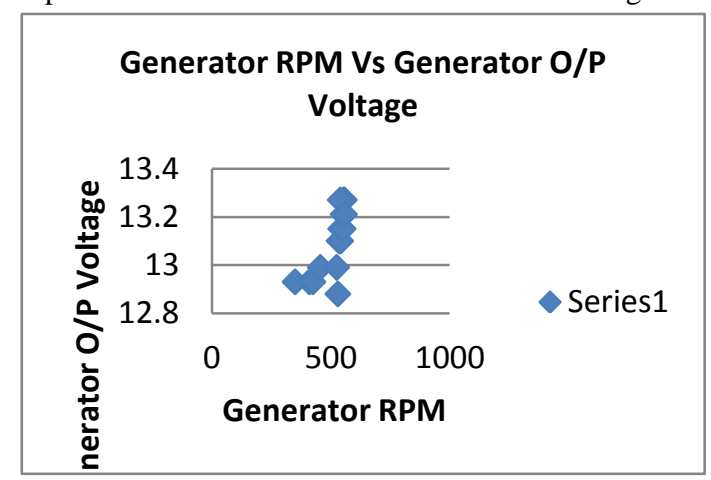

Fig 6: Graph of Generator RPM Vs Generator O/P Voltage

3) Graph of Generator O/P Current Vs Generator O/P Power

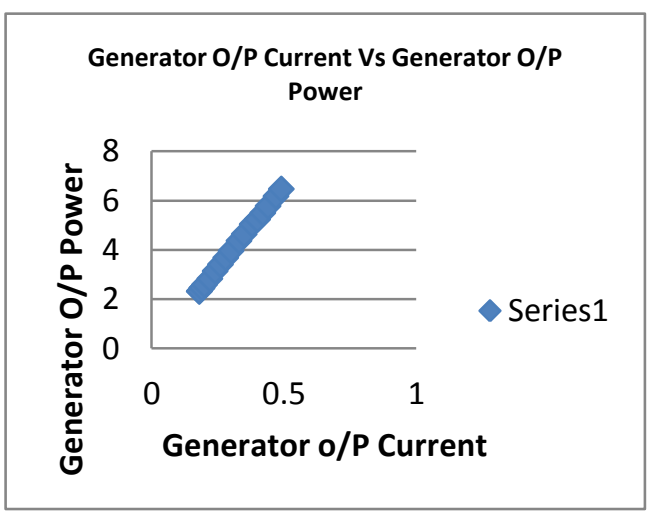

Figure 7: Graph of Generator O/P Current Vs Generator O/P Power 


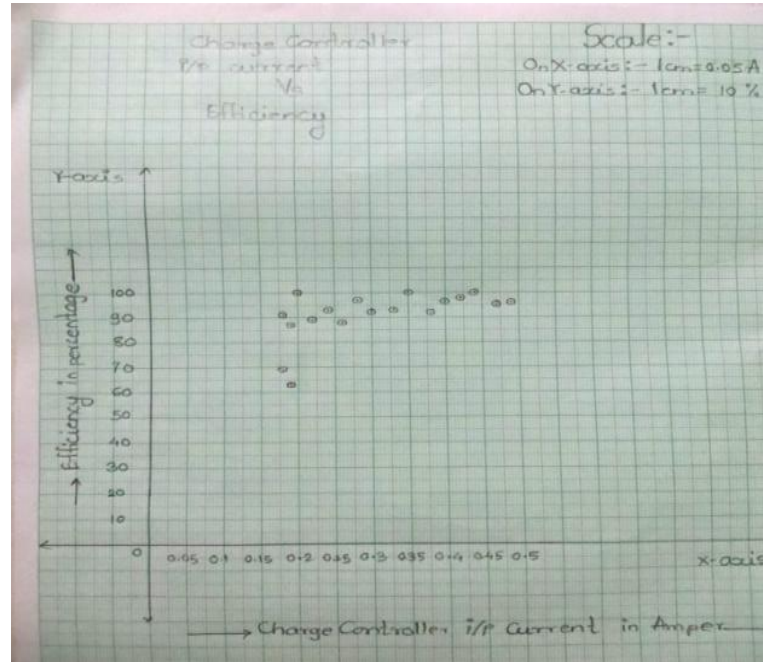

Fig 8: Graph of Charge controller I/P Current Vs Efficiency

5) Graph of Charge controller I/P Voltage Vs Efficiency

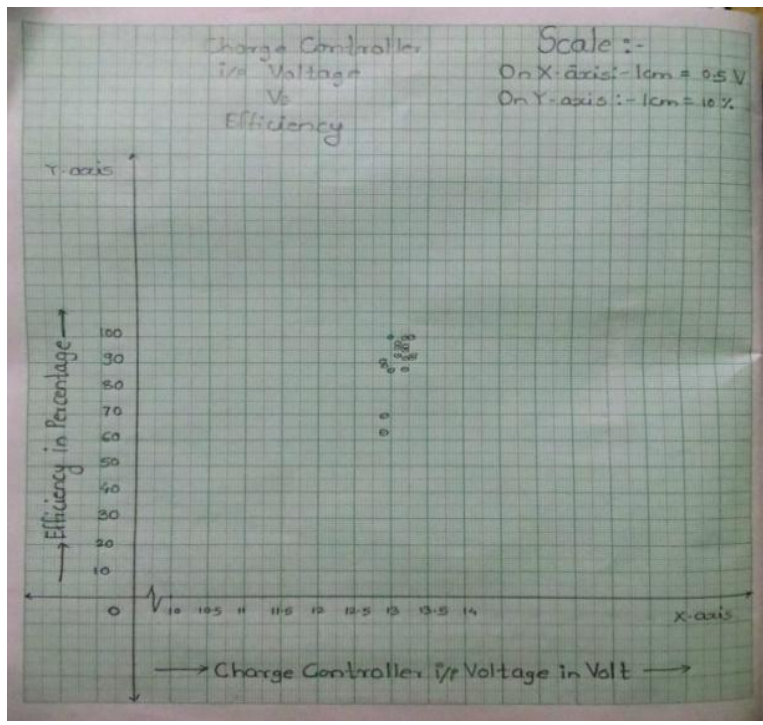

Figure 9: Graph of Charge controller I/P Voltage Vs Efficiency

\section{CONCLUSION}

The effort made by research work by using PWM technique exploits the opportunity of increasing the battery life \& its safety. In a off-grid system in addition to limiting the voltage this charge controllers makes arrangement to an alternative load source to increase the system efficiency. This MPPT technique improves the quantity of service in off-grid system. Further the results shows that use of PWM technique with MPPT increases the efficiency of charge controller up to $92 \%$ under different laboratory conditions as compared to normal charge controllers without MPPT having efficiencies up to 52 to $60 \%$. The care has been taken to avoid the battery deep discharge in design of charge controller circuit. The main aim of charge controller circuit is to increase the safety of battery.

\section{REFERENCES}

[1] Md. Anwarul Azim, S. M. Ariful Huda, Hafizal Mohammad, Nowshad Amin, "Microcontroller Based Standalone PV system for Wireless Sensor Node" in the IEEE Proceedings of the International Conference on Computer and Communication Engineering 2008 May 1315, 2008 Kuala Lumpur, Malaysia, ISBN: 978-1-4244$1692-9$.

[2] L. Maharjan, S. Inoue, H. Akagi, and J. Asakura, "Stateof-charge (SOC)- balancing control of a battery energy storage system based on a cascade PWM converter," IEEE Trans. Power Electron., vol. 24, no. 6, pp. 16281636, Jun 2009.

[3] A.M De Broe, Member, IEEE, S.Drouilhet, and V. Gevorgian, Member, IEEE "A PEAK POWER TRACKER FOR SMALL WIND TURBINES IN BATTERY CHARGING APPLICATIONS" IEEE Transactions on Energy Conversion, Vol. 14, No. 4, pp. 0885-8969/99,December 1999.

[4] Geeta Laxmanrao Kale, N.N. Shinde "Implementation of Prototype Device - Off Grid - Charge Controller Suitable for Wind Solar Hybrid" I S S N : 2249 - 5762 (On 1 i n e ) IJRMET Vol. 1, Issue 1, Oct. 2011

[5] Guoyi Xu, Student Member, IEEE, Lie Xu, Senior Member, IEEE, D. John Morrow, Member, IEEE, and Dong Chen "Coordinated DC Voltage Control of Wind Turbine With Embedded Energy Storage System" IEEE TRANSACTIONS ON ENERGY CONVERSION, VOL. 27, NO. 4,pp. 0885-8969, DECEMBER 2012.

[6] S. Eren, J. C.Y. Hui, D. To, and D. Yazdani. "A High Performance Wind-Electric Battery Charging System", ISBN: 1-4244-0038-4, IEEE CCECE/CCGEI, Ottawa, May 2006

[7] Muhammad Owais, Muhammad Saleheen Aftab"An Offgrid Model Setup for Wind Electric Conversion System" 978-1-4244-4547-9/09/\$26.00 @ 2009 IEEE TENCON 2009

[8] J. Li, E.Murphy, J.Winnick, and P. A.Kohl, "The effects of pulse charging on cycling characteristics of commercial lithium-ion batteries," J. Power Sources, vol. 102, pp. 302-309, 2001.

[9] M.A. Abdullah, C.W. Tan, A.H.M. Yatim, M.R.D. AlMothafar, S.M. Radaideh " Input Current Control of Boost Converters using Current-Mode Controller Integrated with Linear Quadratic Regulator " INTERNATIONAL JOURNAL of RENEWABLE ENERGY RESEARCH M.A.Abdullah et al., Vol.2, No.2, 2012

[10] Wujong Lee, Byung-Moon Han and Hanju Cha " Battery Ripple Current Reduction in a Three-Phase Interleaved DC-DC Converter for 5kW Battery Charger" 978-1-45770541-0/ 2011 IEEE.

[11] Z. Jiang and R. A. Dougal, "Synergetic control of power converters for pulse current charging of advanced batteries from a fuel cell power source," IEEE Trans. Power Electron., vol. 19, no. 4, pp. 1140-1150, Jul. 2004. 
[12] Hany M. Hasanien, Senior Member, IEEE, and S. M. Muyeen, Senior Member, IEEE "Design Optimization of Controller Parameters Used in Variable Speed Wind Energy Conversion System by Genetic Algorithms" IEEE TRANSACTIONS ON SUSTAINABLE ENERGY, VOL. 3, NO. 2,pp. 1949-3029, APRIL 2012

[13] Sercan Teleke, Student Member, IEEE, Mesut E. Baran, Senior Member, IEEE, Alex Q. Huang, Fellow, IEEE, Subhashish Bhattacharya, Member, IEEE, and Loren Anderson "Control Strategies for Battery Energy Storage for Wind Farm Dispatching" IEEE TRANSACTIONS ON ENERGY CONVERSION, VOL. 24, NO. 3, pp. 08858969 SEPTEMBER 2009.

[14] V. Sharmila Deve and S. Karthiga "ADVANCED CONTROL TECHNIQUES IN VARIABLE SPEED STAND ALONE WIND TURBINE SYSTEM" International Journal of Advances in Engineering \& Technology, March 2012. CIJAET ISSN: 2231-1963 Vol. 3, Issue 1, pp. 549-557.

[15] T. Tafticht, K. Agbossou, Senior Member, IEEE, A. Cheriti, Member IEEE, and M.L. Doumbia, Member IEEE "Output Power Maximization of a Permanent Magnet Synchronous Generator Based Stand-alone Wind Turbine" IEEE ISIE 2006, July 9-12, 2006, Montreal, Quebec, Canada 1-4244-0497-5/06.
[16] O. BA, D.Depernet and P. Ndiaye1 and A. Berthon "Medium power wind mill control for standalone energy generation".

[17] Kuo-Yuan Lo, Yaow-Ming Chen, Senior Member, IEEE, and Yung-Ruei Chang, Member, IEEE" MPPT Battery Charger for Stand-Alone Wind Power System" IEEE TRANSACTIONS ON POWER ELECTRONICS, VOL. 26, NO. 6, pp. 0885-8993,JUNE 2011

[18] Wei Qiao, Member, IEEE, Xu Yang, Student Member, IEEE, and Xiang Gong, Student Member, IEEE "Wind Speed and Rotor Position Sensorless Control for DirectDrive PMG Wind Turbines" IEEE TRANSACTIONS ON INDUSTRY APPLICATIONS, VOL. 48, NO. 1,pp. 0093 9994, JANUARY/FEBRUARY 2012

[19] C.-C. Huang and M.-Y. Lin, "A Study of Charging Control of Lead-Acid Battery for Electric Vehicles," Proceedings of the 2000 IEEE International Symposium on Industrial Electronics, Vol.1, pp. 135-140, December 2000 .

[20] J. J. A. Wilkinson and G.A. Covic, "A new pulse charging methodology for lead acid batteries," IPENZ Transactions, Vol. 25, No.1I, November 1998. 